\title{
Transcriptional signature in microglia isolated from an Alzheimer's disease mouse model treated with scanning ultrasound
}

Gerhard Leinenga ${ }^{1 *}$, Liviu-Gabriel Bodea ${ }^{1 *}$, Jan Schröder ${ }^{2 *}$, Giuzhi Sun $^{2}$, Yi Chen², Alexandra Grubman ${ }^{2+}$, Jose M. Polo ${ }^{2+}$ and Jürgen Götz ${ }^{1+}$

${ }^{1}$ Clem Jones Centre for Ageing Dementia Research, Queensland Brain Institute, The University of Queensland, Brisbane (St Lucia Campus), QLD 4072, Australia. ${ }^{2}$ Department of Anatomy \& Developmental Biology and the Australian Regenerative Medicine Institute, Monash University, Melbourne, Victoria 3800, Australia.

* These authors contributed equally to this work.

+ Corresponding authors: j.goetz@uq.edu.au / j.goetz.brisbane@gmail.com, jose.polo@monash.edu, alexandra.grubman@monash.edu

\section{Abstract}

Rationale: Intracranial scanning ultrasound combined with intravenously injected microbubbles (SUS ${ }^{+\mathrm{MB}}$ ) has been shown to transiently open the blood-brain barrier and reduce amyloid- $\beta$ (A $\beta$ ) pathology in the APP23 mouse model of Alzheimer's disease (AD). This has been accomplished, at least in part, through the activation of microglial cells; however, their response to the SUS treatment is only incompletely understood.

Methods: Wild-type (WT) and APP23 mice were subjected to SUS ${ }^{+M B}$, using non-SUS ${ }^{+{ }^{+M B}}$ treated mice as sham controls. After 48 hours, the APP23 mice were injected with methoxy$\mathrm{XO} 4$ to label $\mathrm{A} \beta$ aggregates, followed by microglial isolation into $\mathrm{XO}^{+}$and $\mathrm{XO}^{-}$ populations using flow cytometry. Both $\mathrm{XO}^{+}$and $\mathrm{XO}^{-}$cells were subjected to RNA sequencing and their transcriptome was analyzed through a bioinformatics pipeline.

Results: The transcriptomic analysis of the microglial cells revealed a clear segregation depending on genotype (AD model versus WT mice), as well as treatment (SUS ${ }^{+\mathrm{MB}}$ versus sham) and $\mathrm{A} \beta$ internalization ( $\mathrm{XO}^{+}$versus $\mathrm{XO4}-$ microglia). Differential gene expression analysis detected 278 genes that were significantly changed by $\mathrm{SUS}^{+\mathrm{MB}}$ in the $\mathrm{XO}^{+}$cells (248 up/30 down) and 242 in XO- cells ( 225 up/17 down). Not surprisingly given previous findings of increased phagocytosis of plaques following $\mathrm{SUS}^{+\mathrm{MB}}$, the pathway analysis highlighted that the treatment induced an enrichment in genes related to the phagosome 
pathway in $\mathrm{XO}^{+}$microglia; however, when comparing $\mathrm{SUS}^{+\mathrm{MB}}$ to sham, the analysis revealed an enrichment in genes involved in the cell cycle in both the $\mathrm{XO}_{4}^{+}$and $\mathrm{XO}^{-}$ microglial population.

Conclusion: Our data provide a comprehensive analysis of microglia in an AD mouse model subjected to ultrasound treatment as a function of $A \beta$ internalization, one of the defining hallmarks of AD. Several differentially expressed genes are highlighted, pointing to an ultrasound-induced activation of cell cycle mechanisms in microglial cells isolated from APP23 mice treated with SUS ${ }^{+M B}$.

Keywords: Alzheimer's disease, microglia, ultrasound, transcriptomics, RNA sequencing, methoxy-XO4

\section{Introduction}

Alzheimer disease (AD) is the most common cause of dementia worldwide. The disease is characterized by progressive and irreversible neurodegeneration. However, given the complexity of the disease combined with a lack of knowledge on how to treat AD efficiently, there is an acute requirement to develop novel treatment strategies [1].

At a histopathological level, AD is characterized by the accumulation of extracellular amyloid- $\beta(\mathrm{A} \beta)$ plaques, intraneuronal tau deposits and increased microglial activation [2]. A broad range of studies have revealed how microglial cells assume both a protective role (through shielding, recognition and removal of $A \beta$ ) and a detrimental role (through removal of synapses or release of neurotoxic factors), driving the progression of AD [3].

Transcriptomic studies on microglia have advanced our understanding of the pathogenesis of $\mathrm{AD}$ at the level of transcriptional network dynamics, highlighting important molecular players depending on the different phases of the disease [4-6]. Microglia are known to phagocytose aggregated forms of $A \beta$, and it has been proposed that deficiencies in this process may contribute to late-onset $\mathrm{AD}$ [7] and metabolic labelling in humans indicated that clearance of $\mathrm{A} \beta$ is impaired in $\mathrm{AD}$ [8]. Recently, it has been shown that microglia that have taken up amyloid differ in their transcriptional signature in comparison with microglia that do not contain amyloid [9].

An obstacle to treating AD is the blood-brain barrier which prevents large molecules such as antibodies from entering the brain, with IgG having $0.1 \%$ transfer across the blood- 
brain-barrier (BBB) [10]. Approaches to modify anti-A $\beta$ antibodies to increase levels in the brain are in development [11] along with other approaches to circumvent the BBB.

Studies in animal models of AD have indicated that repeated transient blood-brain barrier (BBB) openings that are achieved throughout the entire brain using intracranial ultrasound in a scanning mode together with intravenously injected microbubbles (SUS ${ }^{+M B}$ ) significantly clear amyloid plaques. One study reported that plaque reduction can occur as fast as 48 hours after BBB opening [12], and we have shown that this process occurs through microglial phagocytosis [13]. Ultrasound-mediated bioeffects including microglial activation have also been demonstrated by specifically targeting the hippocampus $[14,15]$, but the therapeutic benefit seems to be most pronounced when the brain is treated more globally [13]. Of note, this clearing process requires BBB opening [16] and is even effective at reducing $A \beta$ pathology in 22-month-old senescent mice [17]. Combination treatments with ultrasound for delivery of anti-A $\beta$ antibodies such as Aducanumab that has been recently approved by the FDA [18], or an anti-pyroglutamylated A $\beta$ antibody [19], led to more effective plaque removal and behavioral improvements than in those observed in mice that were treated with either ultrasound alone or antibodies alone.

Ultrasound-mediated BBB opening has also been achieved in a small safety trial that revealed tolerability in patients with mild $\mathrm{AD}$ when a small region of the frontal cortex was targeted [20]. A subsequent study found that the BBB could be opened in parts of the hippocampus [21], with a modest reduction in the amyloid PET signal following three treatments with ultrasound over a 6-month period [22]. In all these studies, BBB opening by ultrasound was shown to be safe and reversible in that the BBB was fully restored after 24 hours.

Several mechanisms have been proposed to explain how BBB opening leads to amyloid plaque reduction, including the uptake of endogenous immunoglobulins [23] or albumin binding to amyloid [13], followed by microglial phagocytosis of A $\beta$ and lysosomal digestion. Here, to gain a better understanding of how the combination of SUS treatment and $A \beta$ internalization affects microglial cells, we analyzed the transcriptional profile of microglia isolated from APP23 mice (a model of AD) that had been subjected to SUS ${ }^{+M B}$. By using a fluorescent dye to detect $A \beta$ internalization within the microglia we identified differences between the microglial cells from mice treated with or without ultrasound, as well as between cells that had internalized $A \beta$ or not.

\section{Materials and methods}




\section{Animals}

In this study, we have used APP23 mice (harboring the AD Swedish K670M, N671L double mutation in the APP gene [24]) and wild-type (WT) mice. The animals were maintained on a $12 \mathrm{~h}$ light/dark cycle and housed in a PC2 facility with ad libitum access to food and water. All experimental procedures in this study (Fig 1A) were approved by the University of Queensland Animal Ethics Committee (AEC) (QBI/412/14/NHMRC and QBI/554/17/NHMRC), and Monash University AEC (17241) and were conducted in compliance with the ARRIVE guidelines (Animal Research: Reporting in Vivo Experiments).

\section{SUS treatment}

Microbubbles comprising a phospholipid shell and octafluoropropane gas core were prepared in-house. 1,2-distearoyl-sn-glycero-3-phosphocholine (DSPC) and 1,2-distearoyl-sn-glycero3-phosphoethanolamine-N-[amino(polyethylene glycol)-2000] (DSPE-PEG2000) (Avanti Polar Lipids) were mixed in a 9:1 molar ratio and dissolved in chloroform (Sigma), after which the chloroform solvent was evaporated under vacuum. The dried phospholipid cake was then dissolved in PBS with 10\% glycerol to a concentration of $1 \mathrm{mg}$ lipid/ml and heated to $55^{\circ} \mathrm{C}$ in a sonicating water bath. The solution was placed in a $1.5 \mathrm{ml}$ glass highperformance liquid chromatography (HPLC) vial with the air in the vial replaced with octafluoropropane gas (Arcadophta). The microbubbles were activated on the day of the experiment by agitation of the vial in a dental amalgamator at 4,000 rpm for $45 \mathrm{~s}$. Activated microbubbles were measured with a Multisizer $4 \mathrm{e}$ coulter counter which reported a mean diameter of $1.885 \mu \mathrm{m}$ and a concentration of $9.12 \times 10^{8}$ microbubbles $/ \mathrm{ml}$. These microbubbles were also observed to be polydisperse under a microscope (Fig 1B).

For treatment delivery, an integrated focused ultrasound system (Therapy Imaging Probe System, TIPS, Philips Research) was used. This system consisted of an annular array transducer with a natural focus of $80 \mathrm{~mm}$, a radius of curvature of $80 \mathrm{~mm}$, a spherical shell of $80 \mathrm{~mm}$ with a central opening of $31 \mathrm{~mm}$ diameter, a 3D positioning system, and a programmable motorized system to move the ultrasound focus in the $\mathrm{x}$ and $\mathrm{y}$ planes to cover the entire brain area. A coupler mounted to the transducer was filled with degassed water and 
placed on the head of the mouse with ultrasound gel for coupling, to ensure unobstructed propagation of the ultrasound to the brain.

For SUS ${ }^{+M B}$ applications, mice were anesthetized with ketamine $(90 \mathrm{mg} / \mathrm{kg})$ and xylazine $(6 \mathrm{mg} / \mathrm{kg})$ and the hair on their head was shaved and depilated. They were then injected retro-orbitally with $1 \mu \mathrm{l} / \mathrm{g}$ body weight of microbubble solution and placed under the ultrasound transducer with the head immobilized. A heating pad was used to maintain body temperature. Parameters for the ultrasound delivery were $1 \mathrm{MHz}$ center frequency, $0.65 \mathrm{MPa}$ peak negative pressure, $10 \mathrm{~Hz}$ pulse repetition frequency, $10 \%$ duty cycle, and a 6 second sonication time per spot. The focus of the transducer was $1.5 \mathrm{~mm} \times 12 \mathrm{~mm}$ in the transverse and axial planes, respectively. The motorized positioning system moved the focus of the transducer array in a grid with $1.5 \mathrm{~mm}$ spacing between individual sites of sonication so that ultrasound was delivered sequentially to the entire brain as described previously $[13,18]$. Mice typically received a total of 24 spots of sonication in a $6 \times 4$ raster grid pattern. For the sham treatment, mice received all injections and were placed under the ultrasound transducer, but no ultrasound was emitted. The time between injecting microbubbles and commencing ultrasound delivery was $60 \pm 10 \mathrm{~s}$ and the duration of sonication was approximately $3 \mathrm{~min}$ (total time from microbubble injection approximately $4 \mathrm{~min}$ ).

\section{Acute isolation of microglia and fluorescence activated cell sorting}

Two hours prior to brain harvest, mice were injected intraperitoneally with methoxy-X04 (2 $\mathrm{mg} / \mathrm{ml}$ in $1: 1$ ratio of DMSO to $0.9 \%(\mathrm{w} / \mathrm{v}) \mathrm{NaCl}, \mathrm{pH} 12)$ at $5 \mathrm{mg} / \mathrm{kg}$. Mice were euthanized by $\mathrm{CO}_{2}$ and transcardially perfused with ice-cold PBS prior to brain extraction. Whole brains, excluding the brain stem, olfactory bulbs and cerebellum, were dissected for microglial isolation. Single cell suspensions were prepared by mechanical dissociation using meshes of decreasing sizes from $250 \mu \mathrm{m}$ to $70 \mu \mathrm{m}$ and suspensions were enriched for microglia by density gradient separation. Briefly, the cell pellet was resuspended in $70 \%(\mathrm{v} / \mathrm{v})$ isotonic Percoll (1x PBS + $90 \%$ (v/v) Percoll), overlayed with $37 \%$ (v/v) isotonic Percoll and centrifuged with slow acceleration and no brake at $2,000 \mathrm{~g}$ for $20 \mathrm{~min}$ at $4{ }^{\circ} \mathrm{C}$. The microgliaenriched cell population isolated from the $37 \%-70 \%$ interphase was diluted 1:5 in ice-cold PBS and recovered by cold centrifugation at maximum speed for $1 \mathrm{~min}$ in microcentrifuge tubes. The cell pellet was then stained with antibodies to microglial cell surface markers (CD11b-PE Cy7, 1:200 Biolegend, \# 101216; CD45-APC Cy7, 1:200, BD Biosciences \# 103116;) for isolation using the FACSAria ${ }^{\mathrm{TM}}$ III cell sorter (Fig 1C). For mice without 
endogenous expression of CX3CR1-GFP, CX3CR1 was stained using CX3CR1-FITC (1:100, Biolegend, \#149019). Microglia were defined as live/propidium iodide (PI) ${ }^{-}$(SigmaAldrich, St. Louis, MO, \#P4864), CD11b ${ }^{+}, \mathrm{CD} 45^{\text {low }}, \mathrm{CX} 3 \mathrm{CR} 1^{+}$cells. The XO4 ${ }^{+}$population gate was set using methoxy-XO4-injected wild-type animals. $\mathrm{X} 4^{+}$and $\mathrm{X} 04^{-}$microglial populations were sorted separately for further analysis.

\section{Immunohistology}

APP23 mice were treated with SUS ${ }^{+M B}$ and were perfused with PBS and drop fixed in 4\% paraformaldehyde in PBS. They were then cryoprotected in 30\% sucrose in PBS and sectioned at $40 \mu \mathrm{m}$ with a freezing sliding microtome. Microglia were immunostained with anti-Iba1 antibody (Wako, JP 1:1,000) followed by incubation with an anti-rabbit secondary antibody AlexaFluor 568 conjugate (Invitrogen). Sections were then co-stained with $10 \mu \mathrm{M}$ methoxy-XO4 (Tocris Bioscience) in PBS with 20\% ethanol before cover-slipping. Images were obtained with a spinning disk confocal microscope (Nikon Diskovery) with a 20x objective, acquiring z-stacks through the entire depth of the section (Fig 1D).

\section{Bulk RNA-seq and bioinformatics analysis}

RNA extraction from FACS-sorted microglia was performed using the RNeasy Micro Kit (Qiagen, \#74004) and RNA quality was assessed using the Bioanalyser (Agilent RNA 6000 Pico kit; \#5067-1513). The libraries were prepared using microglia RNA samples with RIN value $\geq 7.9$ as previously described [9]. Sequencing reads were mapped to the mouse transcriptome reference genome (GRCm38) using STAR (v020201). We then established read counts for each gene using featureCounts (v1.5.2). The bulk RNA-seq read counts were further analysed using R (v4.0.2), limma (v3.42.2), and edgeR (v3.28.1). Data handling and plotting were performed using tidyverse (v1.3.0). In detail, we first removed lowly or nonexpressed genes with the filterByExpr function, and we calculated TMM (trimmed mean of $\mathrm{m}$-values) normalisation factors to remove composition bias using calcNormFactors. To visualise dimensionality reduction of the sequencing data, we first removed unwanted variation in the data with removeBatchEffect. The principal component analysis (PCA plot, Fig. 2A) is using prcomp and ggplot to visualise the remaining variance in the data. The heatmap (Fig. 2B) is plotting the DEGs from either contrast using the wardD2 method and the pheatmap function. To determine differentially expressed genes (DEGs), we first 
determined the gene-wise variance trends using voom. Then, we built a linear model using the lmFit function and all combinations of genotype and treatment, batch, and sex as covariates. The Venn diagrams (Fig. 3) are generated with the VennDiagram package (v1.7.0). Tables 1,2 show the top 50 DEGs for the two contrasts of interest (ranked by absolute log fold change). Pathway and gene ontology enrichments are calculated from the respective DEG lists using the kegga and goana functions (Tables 3,4).

\section{Results}

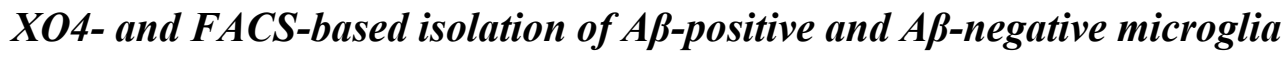

To understand the different effects of ultrasound-mediated BBB opening on plaquephagocytic and non-phagocytic microglia in $\mathrm{AD}$, we applied SUS ${ }^{+\mathrm{MB}}$ or sham (i.e. mice were anaesthetized and injected with microbubbles, but not exposed to ultrasound) to the brains of APP23 mice or WT littermate controls (Fig. 1A,B). In addition, to be able to distinguish between microglial cells that had internalized $A \beta$ and those that had not, we used the fluorescent Congo-red derivative methoxy-XO4 to stain $\mathrm{A} \beta$ within microglia when injected into live mice, as previously done $[9,25]$. This allowed us to use a FACS-based technique to separate and isolate $\mathrm{XO}^{+}$(A $\beta$ phagocytic) and $\mathrm{XO}^{-}$(non-phagocytic) microglia following both SUS ${ }^{+M B}$ and sham treatment paradigms (Fig. 1C,D).

\section{Genotype, treatment and Aß internalization induce distinct phenotypes in microglia}

Sorted microglial cells (both $\mathrm{XO}^{+}$and $\mathrm{XO}^{-}$) from the four experimental groups (Fig. 1A) were subjected to RNA isolation, followed by RNA sequencing (RNAseq) and bioinformatic analysis. Principal component analysis (PCA) revealed a clear segregation between the samples of different genotypes, being either of APP23 mutant or WT origin (Fig. 2A). In addition, both PCA and hierarchical clustering analysis (Fig. 2B) segregated distinct microglial populations induced by $\mathrm{A} \beta$ uptake $\left(\mathrm{XO}^{+}\right.$versus $\mathrm{XO}^{-}$cells), as well as treatment (SUS ${ }^{+\mathrm{MB}}$ versus sham-treated animals), which were markedly accentuated in the APP23 samples. As the effect of treatment in WT mice was negligible and differential expression analysis had revealed no significant changes to the transcriptome, we subsequently focused our analysis on the effects of ultrasound \pm A $\beta$ internalization in APP23-derived microglia only. 


\section{SUS treatment induces an increased number of up-regulated genes in microglia}

To gain insight into the response of APP23 microglia to the SUS treatment regime, we further analyzed the transcripts obtained from $\mathrm{XO}^{+}$and $\mathrm{XO}^{-}$cells. Our analysis identified 397 differentially enriched genes (FDR $\leq 0.05$ ), with 155 genes being specific for $\mathrm{XO}^{+}$cells, 199 genes specific for $\mathrm{XO}^{-}$microglia, and 123 genes being independent of the $\mathrm{A} \beta$ signature. Analyzing the treatment-dependency patterns, we observed that most of the up-regulated genes were induced by SUS ${ }^{+M B}$, with a total of 353 enriched genes across all the $A \beta$ internalization levels (Fig. 3A), and only 44 genes that were down-regulated following SUS $^{+M B}$ treatment (Fig. 3B). These enrichment patterns are highlighted in more detail by the Volcano plots, with both the $\mathrm{XO}^{+}$cells (Fig. 4A) and $\mathrm{XO}^{-}$cells (Fig. 4B) exhibiting increased numbers of differentially enriched genes induced by the SUS ${ }^{+M B}$ treatment. The top 50 differentially expressed genes in the $\mathrm{SUS}^{+\mathrm{MB}}$ versus sham groups for both $\mathrm{XO}^{+}$and $\mathrm{XO}^{-}$ microglia are presented in Tables 1 and 2.

\section{SUS treatment induces an enrichment in microglial cell-cycle-related transcriptome}

We next sought to identify the functionally enriched pathways induced by SUS treatment and compare them in both the $\mathrm{XO}^{+}$and $\mathrm{XO}^{-}$microglia. Applying a gene ontology (GO) enrichment analysis to the SUS ${ }^{+M B}$ versus sham datasets revealed the top 10 enriched pathways that included 'cell cycle', 'DNA replication' and 'DNA metabolic processes' (Table 3). KEGG pathway analysis revealed that the most enriched pathways included 'DNA replication' and 'cell cycle', as well as established pathways in relation to the role of microglia in $\mathrm{AD}$, such as 'phagosome' and the 'complement and coagulation cascade' (Table 4). Inspection of the 'cell cycle' and 'phagosome' pathways in a treatment- (SUS ${ }^{+M B}$ versus sham) and $\mathrm{A} \beta$ internalization ( $\mathrm{XO}^{+}$versus $\left.\mathrm{XO}^{-}\right)$-dependent manner revealed similar trends, with a stronger response found for the $\mathrm{XO} 4+$ microglia containing internalized $\mathrm{A} \beta$ (Fig. 5). More genes in the phagosome pathway are significantly altered by SUS in XO4+ microglia (7 genes up-regulated and 3 down-regulated) than XO4- microglia (5 genes up-regulated) with 2 of these genes up-regulated in both (Fig. 5a). For the cell cycle pathway there were also more genes up-regulated in XO4+ microglia (18 genes up-regulated) than XO4microglia (11 genes-upregulated with 9 of these genes up-regulated in both (Fig. 5b). 


\section{Discussion}

In this study, we sought to investigate how the application of BBB opening achieved with therapeutic ultrasound in conjunction with intravenously injected microbubbles changes the microglial transcriptomic profile in a mouse model of AD. This profile was obtained by analyzing the microglial transcriptome and correlating it with the presence or absence of $A \beta$ in the microglia at 48 hours after treating amyloid-depositing APP23 mice with SUS ${ }^{+\mathrm{MB}}$. This allowed us to identify several cellular functions that were increased by SUS ${ }^{+M B}$ application, such as the phagosome (as would have been expected in $\mathrm{A} \beta$-containing $\mathrm{XO}^{+}$cells), as well as members of the cell cycle pathway, which were upregulated independent of the $A \beta$ internalization level. Our findings further indicate that BBB opening by ultrasound has lasting immunomodulatory effects in the context of AD.

Several previous studies have investigated the effect of ultrasound application to the brain by applying -omics techniques to cell populations. One study investigating ultrasoundmediated delivery of plasmids to the brain of WT mice performed single-cell RNA sequencing and found an upregulation of lysosomal genes in microglia 48 hours after ultrasound treatment [26]. In support of this, in a SWATH quantitative proteomics screen following a series of six weekly sessions of SUS treatments (SUS ${ }^{+M B}$ ) in aged wild-type C57Bl/6 mice, we identified an increase in two microglial proteins (LRBA and CAGP) which are involved in phagocytosis [27].

In aiming to find a treatment modality for $\mathrm{AD}$, boosting the $\mathrm{A} \beta$ phagocytic activity of microglia may present a promising strategy if applied to the earliest stages of the disease, by increasing the clearance of protein deposits [28]. A previous attempt to investigate the microglial response following ultrasound treatment focused on investigating transcripts related to the downstream effects of the NFKB pathway and damage-associated molecules in bulk lysates from WT rodent brains, with most transcript levels returning to baseline after 24 hours [29]. The study concluded that ultrasound treatment with BBB opening may lead to sterile inflammation. A subsequent study, however, reported no significant changes in the expression of any of the NFKB-related genes when using a lower, more clinically relevant dose of microbubbles [30]. These opposing effects could be attributed to the specific ultrasound treatment parameters that elicit a cavitation-modulated inflammatory response through the microbubbles present in the blood circulation [31]. In addition, the transcriptomic response to ultrasound-induced $\mathrm{BBB}$ opening was found to be dependent on the type of anesthesia used during the procedure [26]. Of note, we used ultrasound settings that we have 
previously demonstrated to increase microglial phagocytosis [13], cause no damage to neurons [32], and which we suggest have relatively lower levels of cavitation and BBB opening. Taken together, these results indicate that the magnitude of the effects of ultrasound-mediated BBB opening are heavily dependent on the parameters of ultrasound used as well as the downstream analysis (RNA or protein, and heterogeneous tissue or isolated cell-types).

Using a protocol that we have recently applied to reveal the transcriptional signature of microglia associated with $\mathrm{A} \beta$ phagocytosis [9], in the current study, we aimed to investigate changes after SUS treatment in the APP23 model of AD. Our results revealed enriched pathways in the $A \beta$-containing microglia, such as cell cycle, phagosome, complement activity, and metabolism. Some of the pathways identified by our analysis have previously been associated with microglial activation in $\mathrm{AD}$, validating our results. Indeed, microglia have been observed to remove synapses in AD through a mechanism involving members of the complement system [33, 34]. In addition, it has been proposed that the metabolism of microglia is impaired in $\mathrm{AD}$, an effect that can be ameliorated by enhancing the cellular energetic and biosynthetic metabolism [35]. Increased microglia numbers in proximity to plaques are associated with more compact plaques and reduced axonal dystrophy [36], and we have previously reported increased microglial numbers around plaques following SUS ${ }^{+M B}$ treatment [17]. Higher numbers of microglia around plaques may result from an increased proliferation or metabolic activity, as hinted in the present study. The reactivation of the cell-cycle machinery in microglia following ultrasound treatment is of particular interest, as it has recently been reported that repopulating microglial cells following ablation are neuroprotective in $\mathrm{AD}[37,38]$.

In conclusion, we have examined the effect of $\mathrm{SUS}^{+\mathrm{MB}}$ on the microglial transcriptome in the presence or absence of amyloid pathology. SUS ${ }^{+M B}$ leads to temporary opening of the $\mathrm{BBB}$ and alters microglial gene expression in the $\mathrm{AD}$ brain to modulate several cellular pathways, including the cell cycle, various metabolic pathways and the phagosome. Harnessing the protective effects of microglia in the context of AD could potentially be achieved by a combination of $\mathrm{SUS}^{+} \mathrm{MB}$-mediated BBB opening and targeted drug delivery.

\section{Abbreviations}

AD: Alzheimer's disease; A $\beta$ : amyloid-beta; BBB: blood brain barrier; FACS: fluorescence activated cell sorting; MBs: microbubbles; NFкB: nuclear factor kappa light chain enhancer 
of activated B cells; PBS: phosphate-buffered-saline; PCA: principal components analysis;

SUS: scanning ultrasound; WT: wild-type

\section{Credit author statement}

GL, GS and AG performed experiments. GL, LGB, JS, YC, and AG analyzed data. GL, LGB, JS, JP and JG wrote the manuscript with input from all the authors.

\section{Acknowledgements}

The authors would like to acknowledge Flowcore, Monash Health Translation Precinct Medical Genomics Facility, and Australian Research Laboratories/Monash Animal Research Platform, Monash University, for the provision of instrumentation, training and technical support. We thank Tishila Palliyaguru and Linda Cumner for assistance with animal colonies, and Rowan Tweedale for critical reading of the manuscript.

\section{Funding}

We acknowledge support by the Estate of Dr Clem Jones AO, the National Health and Medical Research Council of Australia [GNT1145580, GNT1176326], and the State Government of Queensland (DSITI, Department of Science, Information Technology and Innovation) to JG. The Australian Regenerative Medicine Institute is supported by grants from the State Government of Victoria and the Australian Government. A.G was funded by a NHMRC- ARC Dementia Fellowship and A.G. and G.S received funding from Yulgilbar Foundation and Dementia Australia.

\section{Competing Interests}

The authors declare that no competing interest exists.

\section{References}

1. Polanco, J.C., et al., Amyloid-beta and tau complexity - towards improved biomarkers and targeted therapies. Nat Rev Neurol, 2018. 14(1): p. 22-39.

2. De Strooper, B. and E. Karran, The Cellular Phase of Alzheimer's Disease. Cell, 2016. 164(4): p. 603-15.

3. Scheiblich, H., et al., Neuroimmune Connections in Aging and Neurodegenerative Diseases. Trends Immunol, 2020. 41(4): p. 300-312.

4. Zhang, B., et al., Integrated systems approach identifies genetic nodes and networks in late-onset Alzheimer's disease. Cell, 2013. 153(3): p. 707-20. 
5. $\quad$ Keren-Shaul, H., et al., A Unique Microglia Type Associated with Restricting Development of Alzheimer's Disease. Cell, 2017. 169(7): p. 1276-1290 e17.

6. $\quad$ Grubman, A., et al., A single-cell atlas of entorhinal cortex from individuals with Alzheimer's disease reveals cell-type-specific gene expression regulation. Nat Neurosci, 2019. 22(12): p. 2087-2097.

7. $\quad$ Ewers, M., et al., Higher CSF sTREM2 and microglia activation are associated with slower rates of beta-amyloid accumulation. EMBO Mol Med, 2020. 12(9): p. e12308.

8. Mawuenyega, K.G., et al., Decreased clearance of CNS beta-amyloid in Alzheimer's disease. Science, 2010. 330(6012): p. 1774.

9. Grubman, A., et al., Transcriptional signature in microglia associated with Abeta plaque phagocytosis. Nat Commun, 2021. 12(1): p. 3015.

10. Leinenga, G., et al., Ultrasound treatment of neurological diseases - current and emerging applications. Nat Rev Neurol, 2016. 12(3): p. 161-74.

11. Weber, F., et al., Brain Shuttle Antibody for Alzheimer's Disease with Attenuated Peripheral Effector Function due to an Inverted Binding Mode. Cell Rep, 2018. 22(1): p. 149-162.

12. Poon, C.T., et al., Time course of focused ultrasound effects on beta-amyloid plaque pathology in the TgCRND8 mouse model of Alzheimer's disease. Sci Rep, 2018. 8(1): p. 14061.

13. Leinenga, G. and J. Götz, Scanning ultrasound removes amyloid-beta and restores memory in an Alzheimer's disease mouse model. Sci Transl Med, 2015. 7(278): p. 278 ra33.

14. Burgess, A., et al., Alzheimer disease in a mouse model: MR imaging-guided focused ultrasound targeted to the hippocampus opens the blood-brain barrier and improves pathologic abnormalities and behavior. Radiology, 2014. 273(3): p. 736-45.

15. Shen, Y., et al., Ultrasound with microbubbles improves memory, ameliorates pathology and modulates hippocampal proteomic changes in a triple transgenic mouse model of Alzheimer's disease. Theranostics, 2020. 10(25): p. 11794-11819.

16. Leinenga, G., W.K. Koh, and J. Götz, Scanning ultrasound in the absence of bloodbrain barrier opening is not sufficient to clear beta-amyloid plaques in the APP23 mouse model of Alzheimer's disease. Brain Res Bull, 2019. 153: p. 8-14.

17. Leinenga, G. and J. Götz, Safety and Efficacy of Scanning Ultrasound Treatment of Aged APP23 Mice. Front Neurosci, 2018. 12: p. 55.

18. Leinenga, G., W.K. Koh, and J. Götz, A comparative study of the effects of Aducanumab and scanning ultrasound on amyloid plaques and behavior in the APP23 mouse model of Alzheimer disease. Alzheimers Res Ther, 2021. 13(1): p. 76.

19. Sun, T., et al., Focused ultrasound with anti-pGlu3 Abeta enhances efficacy in Alzheimer's disease-like mice via recruitment of peripheral immune cells. J Control Release, 2021. 336: p. 443-456.

20. Lipsman, N., et al., Blood-brain barrier opening in Alzheimer's disease using MRguided focused ultrasound. Nat Commun, 2018. 9(1): p. 2336.

21. Rezai, A.R., et al., Noninvasive hippocampal blood-brain barrier opening in Alzheimer's disease with focused ultrasound. Proc Natl Acad Sci U S A, 2020. 117(17): p. 9180-9182.

22. D'Haese, P.F., et al., beta-Amyloid Plaque Reduction in the Hippocampus After Focused Ultrasound-Induced Blood-Brain Barrier Opening in Alzheimer's Disease. Front Hum Neurosci, 2020. 14: p. 593672.

23. Jordao, J.F., et al., Amyloid-beta plaque reduction, endogenous antibody delivery and glial activation by brain-targeted, transcranial focused ultrasound. Exp Neurol, 2013. 248: p. 16-29. 
24. Götz, J., L.G. Bodea, and M. Goedert, Rodent models for Alzheimer disease. Nat Rev Neurosci, 2018. 19(10): p. 583-598.

25. Bolmont, T., et al., Dynamics of the microglial/amyloid interaction indicate a role in plaque maintenance. J Neurosci, 2008. 28(16): p. 4283-92.

26. Mathew, A.S., C.M. Gorick, and R.J. Price, Single-cell mapping of focused ultrasound-transfected brain. Gene Ther, 2021.

27. Blackmore, D.G., et al., Low-intensity ultrasound restores long-term potentiation and memory in senescent mice through pleiotropic mechanisms including NMDAR signaling. Mol Psychiatry, 2021.

28. Deczkowska, A., et al., Disease-Associated Microglia: A Universal Immune Sensor of Neurodegeneration. Cell, 2018. 173(5): p. 1073-1081.

29. Kovacs, Z.I., et al., Disrupting the blood-brain barrier by focused ultrasound induces sterile inflammation. Proc Natl Acad Sci U S A, 2017. 114(1): p. E75-E84.

30. McMahon, D. and K. Hynynen, Acute Inflammatory Response Following Increased Blood-Brain Barrier Permeability Induced by Focused Ultrasound is Dependent on Microbubble Dose. Theranostics, 2017. 7(16): p. 3989-4000.

31. Ji, R., et al., Cavitation-modulated inflammatory response following focused ultrasound blood-brain barrier opening. J Control Release, 2021. 337: p. 458-471.

32. Hatch, R.J., G. Leinenga, and J. Götz, Scanning Ultrasound (SUS) Causes No Changes to Neuronal Excitability and Prevents Age-Related Reductions in Hippocampal CA1 Dendritic Structure in Wild-Type Mice. PLoS One, 2016. 11(10): p. e0164278.

33. Hong, S., et al., Complement and microglia mediate early synapse loss in Alzheimer mouse models. Science, 2016. 352(6286): p. 712-716.

34. Benetatos, J., et al., PTEN activation contributes to neuronal and synaptic engulfment by microglia in tauopathy. Acta Neuropathol, 2020. 140(1): p. 7-24.

35. Ulland, T.K., et al., TREM2 Maintains Microglial Metabolic Fitness in Alzheimer's Disease. Cell, 2017. 170(4): p. 649-663 e13.

36. Yuan, P., et al., TREM2 Haplodeficiency in Mice and Humans Impairs the Microglia Barrier Function Leading to Decreased Amyloid Compaction and Severe Axonal Dystrophy. Neuron, 2016.90(4): p. 724-39.

37. Sosna, J., et al., Early long-term administration of the CSF1R inhibitor PLX3397 ablates microglia and reduces accumulation of intraneuronal amyloid, neuritic plaque deposition and pre-fibrillar oligomers in 5XFAD mouse model of Alzheimer's disease. Mol Neurodegener, 2018. 13(1): p. 11.

38. Olmos-Alonso, A., et al., Pharmacological targeting of CSF $1 R$ inhibits microglial proliferation and prevents the progression of Alzheimer's-like pathology. Brain, 2016. 139(Pt 3): p. 891-907. 
bioRxiv preprint doi: https://doi.org/10.1101/2021.12.20.473590; this version posted December 21, 2021. The copyright holder for this preprint (which was not certified by peer review) is the author/funder, who has granted bioRxiv a license to display the preprint in perpetuity. It is made available under aCC-BY-NC-ND 4.0 International license.

\section{Graphical abstract}

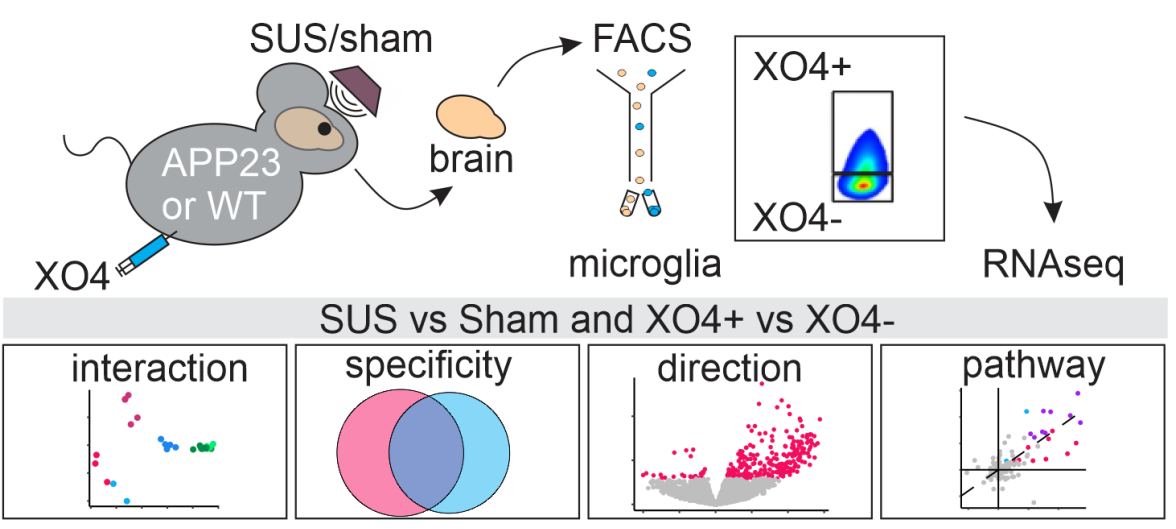


bioRxiv preprint doi: https://doi.org/10.1101/2021.12.20.473590; this version posted December 21, 2021. The copyright holder for this preprint (which was not certified by peer review) is the author/funder, who has granted bioRxiv a license to display the preprint in perpetuity. It is made available under aCC-BY-NC-ND 4.0 International license.

\section{Figures}

A

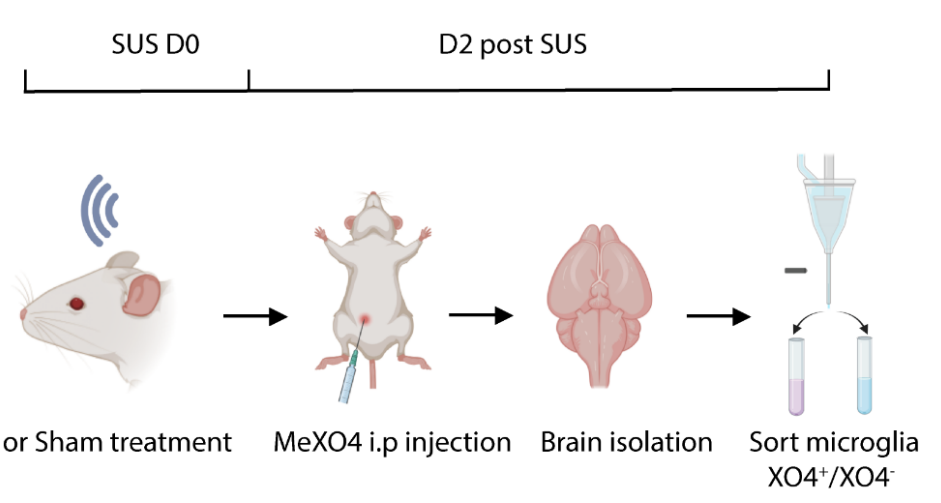

B
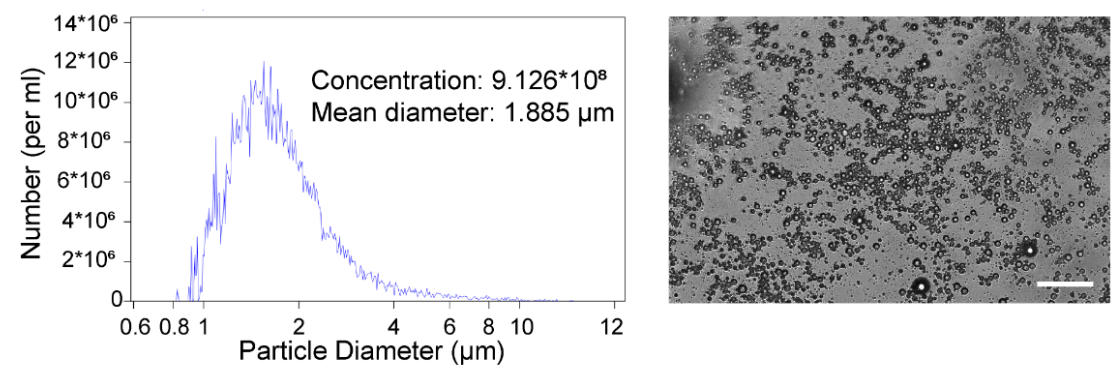

C
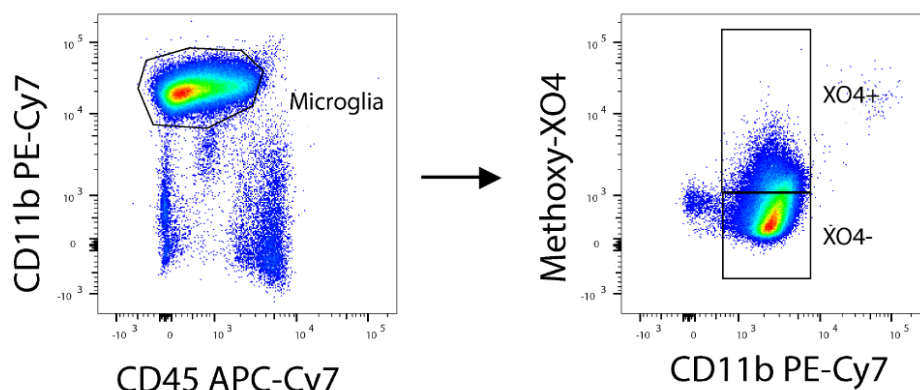

D
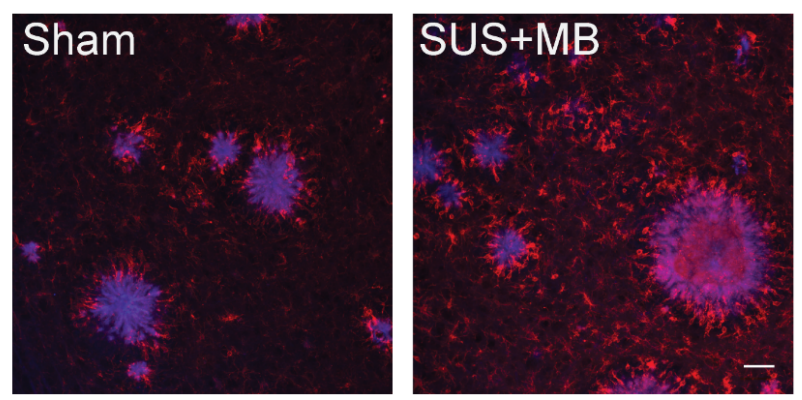
Figure 1. Experimental design and gating strategy to isolate $\mathrm{XO4}^{+}$and $\mathrm{XO4}^{-}$microglia. $^{-}$ (A) Scanning ultrasound (SUS ${ }^{+\mathrm{MB}}$ ) or sham (no ultrasound) treatment was applied to APP23 transgenic and wild-type (WT) mice. Two days post-treatment, the mice received a single injection with methoxy-XO4 that binds $\mathrm{A} \beta$ two hours before euthanasia and collection of brain tissue. The brains of the mice were harvested and lysed to form a single-cell suspension, followed by FACS-based isolation of $\mathrm{XO}^{+}$and $\mathrm{XO}^{-}$microglial cells. (B) Inhouse prepared microbubbles were used for scanning ultrasound $\left(\mathrm{SUS}^{+\mathrm{MB}}\right)$ and their size and concentration were measured by Coulter Counter. (C) The gating strategy used to isolate microglial cells into $\mathrm{XO}^{+}$and $\mathrm{XO}^{-}$populations via FACS using CD11b and CD45 antibodies to isolate a pure population of microglia, and Methoxy-XO4 fluorescence to isolate microglia cells that contain methoxy-XO4 bound to A $\beta$. (D) Methoxy-XO4 binds to A $\beta$ plaques in the brains of APP23 mice (blue) in close proximity to Iba1-positive microglia (red). Scale bar $50 \mu \mathrm{m}$. 
A

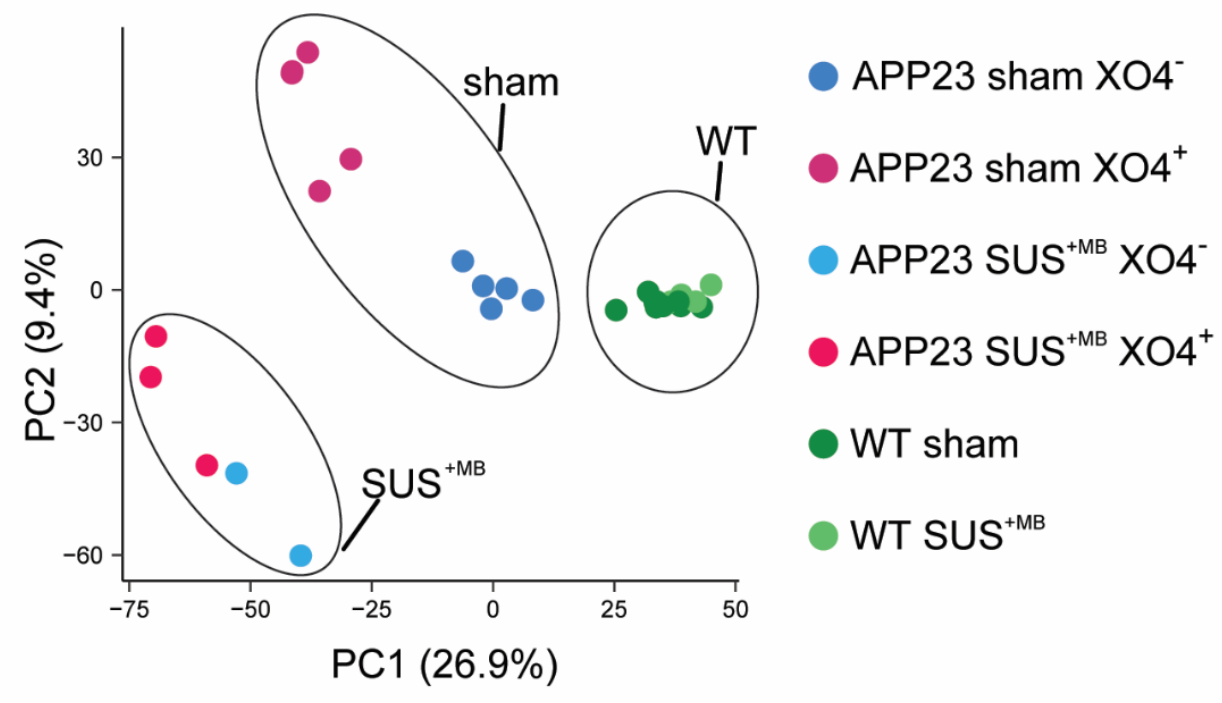

B

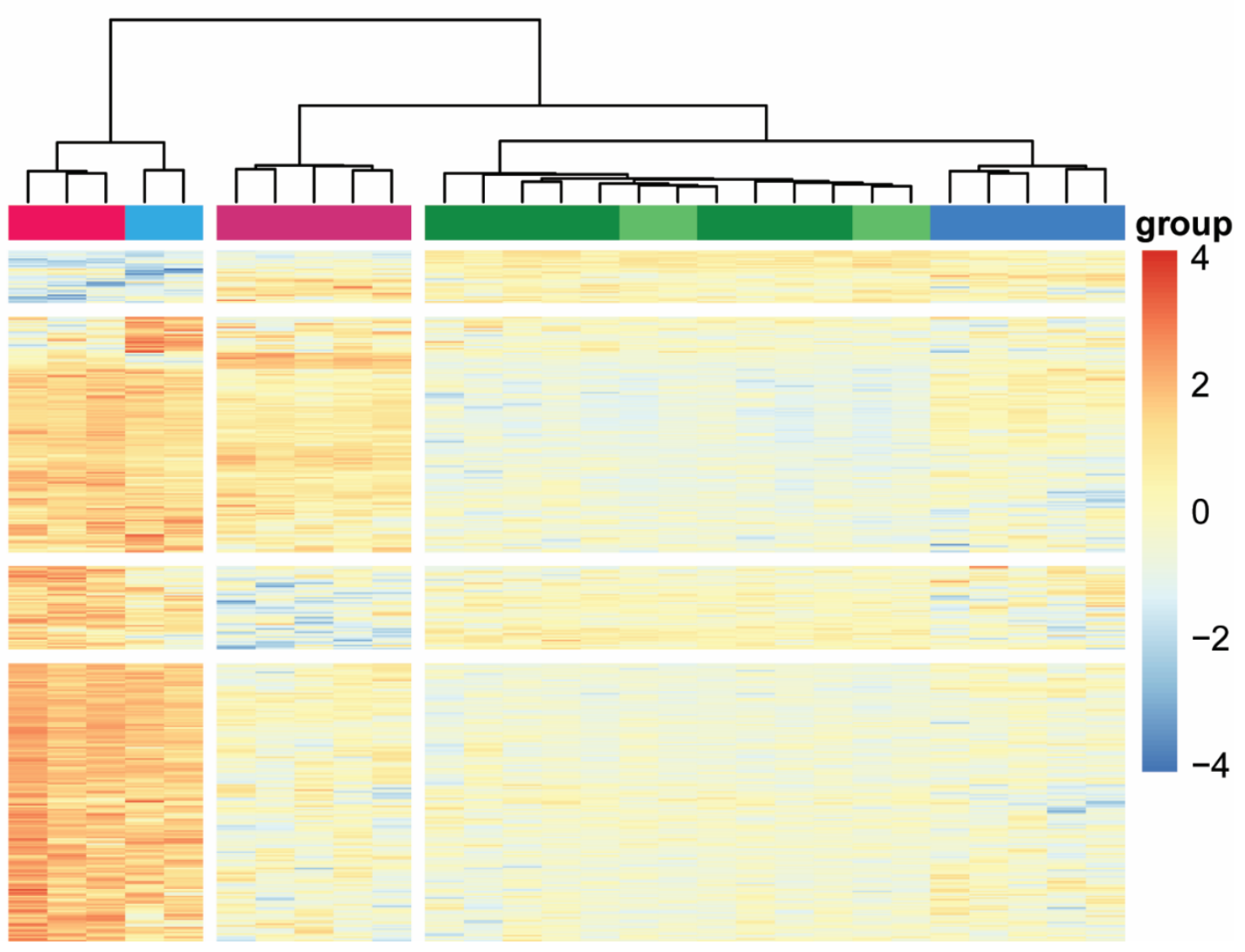


Figure 2. Cluster analysis distinguishes between genotype-, treatment-, and A $\beta$ dependent microglial phenotypes. (A) Principal component analysis reveals the presence of a WT microglia cluster independent of SUS ${ }^{+M B}$ treatment that is segregated from cells of APP23 origin (further clustered dependent on both the SUS ${ }^{+M B}$ treatment and their A $\beta$ content) Ovals indicate treatment groups: $\mathrm{SUS}^{+\mathrm{MB}}$, Sham, and WT mice. (B) Hierarchical clustering of the differential genes (SUS ${ }^{+M B}$ versus sham) reveals a clear segregation between samples of APP23 or WT origin, $\mathrm{SUS}^{+\mathrm{MB}}$ - or sham-treated, and containing A $\beta$ or not. 
A

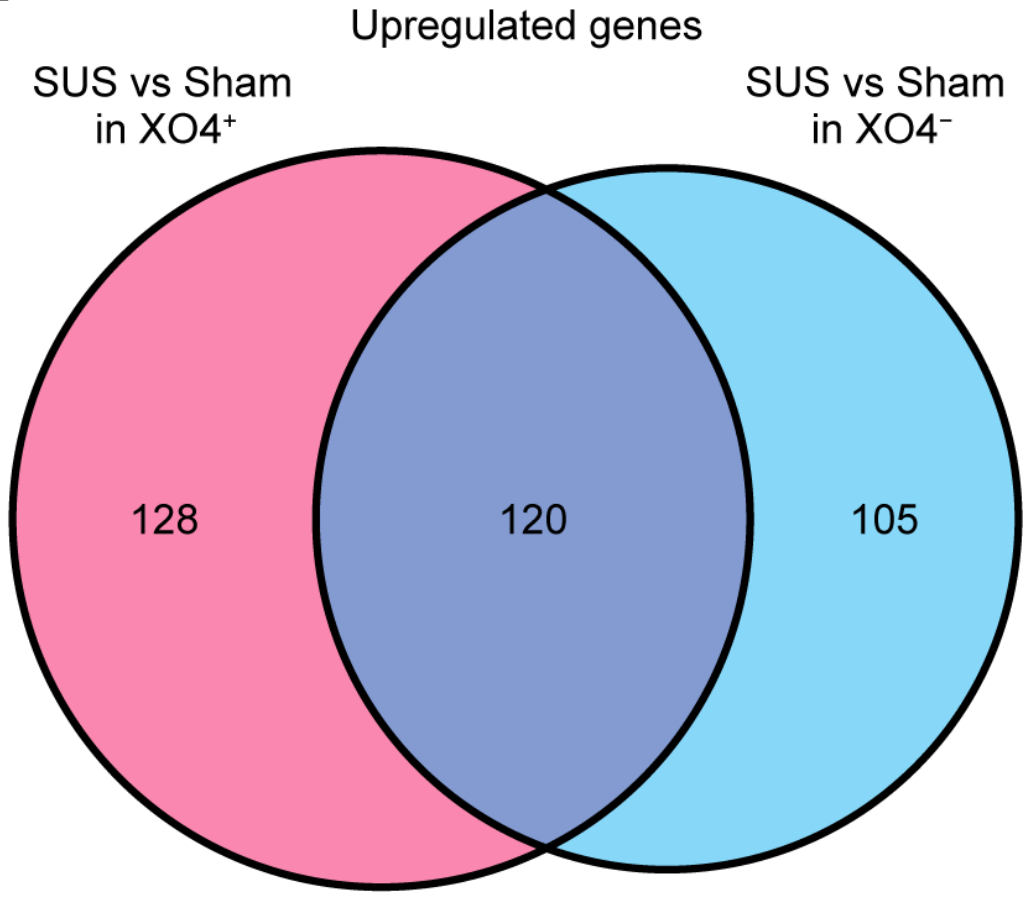

B

Downregulated genes

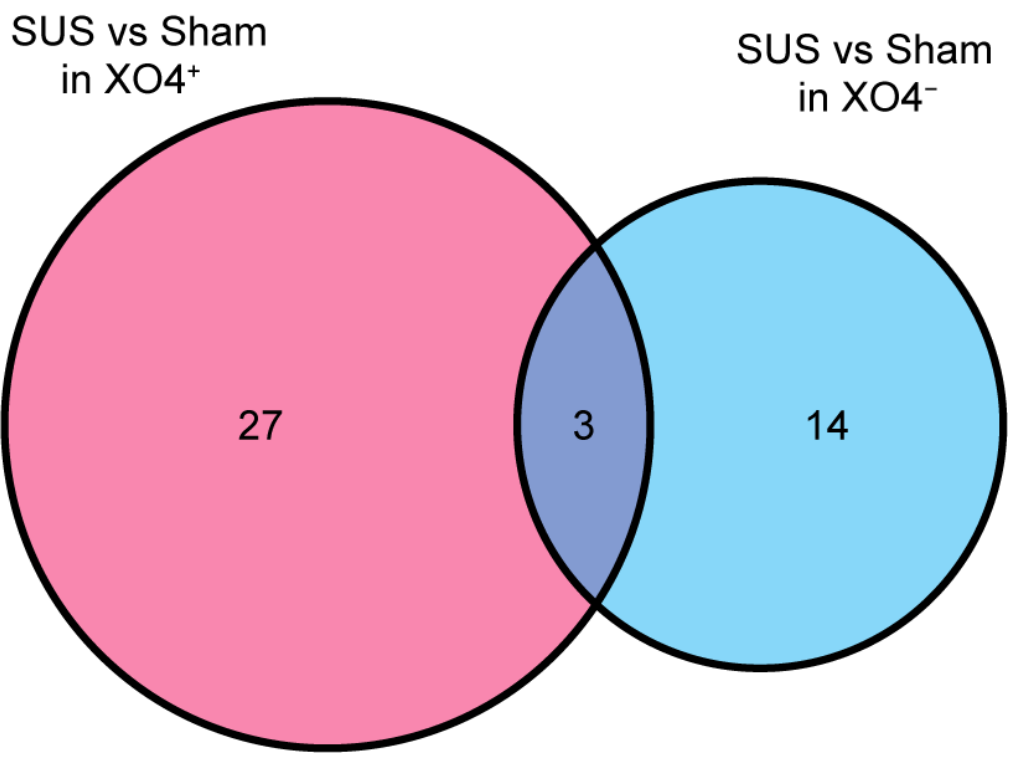


Figure 3. SUS ${ }^{+M B}$ treatment leads to a marked increase in the number of upregulated genes in both $\mathrm{XO4}^{+}$and $\mathrm{XO4}^{-}$microglia, when compared with sham-treated APP23 mice. (A) A Venn diagram depicting the number of genes upregulated by SUS ${ }^{+M B}$ distribute similarly between $\mathrm{XO}^{+}$and $\mathrm{XO}^{-}$cells, with many genes up in both. (B) A larger number of genes were down-regulated in the $\mathrm{XO}^{+}$cells compared with $\mathrm{XO}^{-}$cells following $\mathrm{SUS}^{+\mathrm{MB}}$, with few genes down in both. 


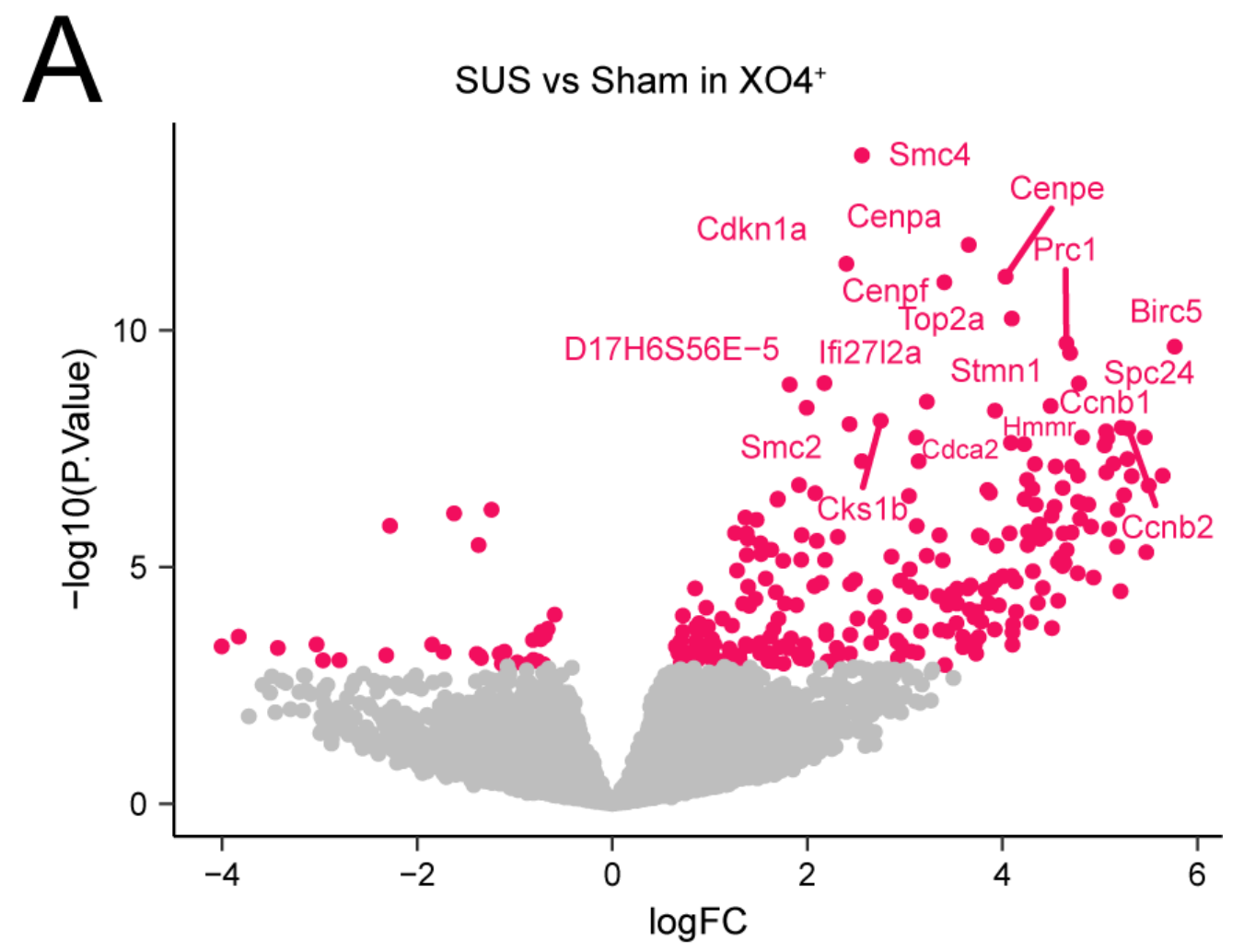

B

SUS vs Sham in $\mathrm{XO}^{-}$

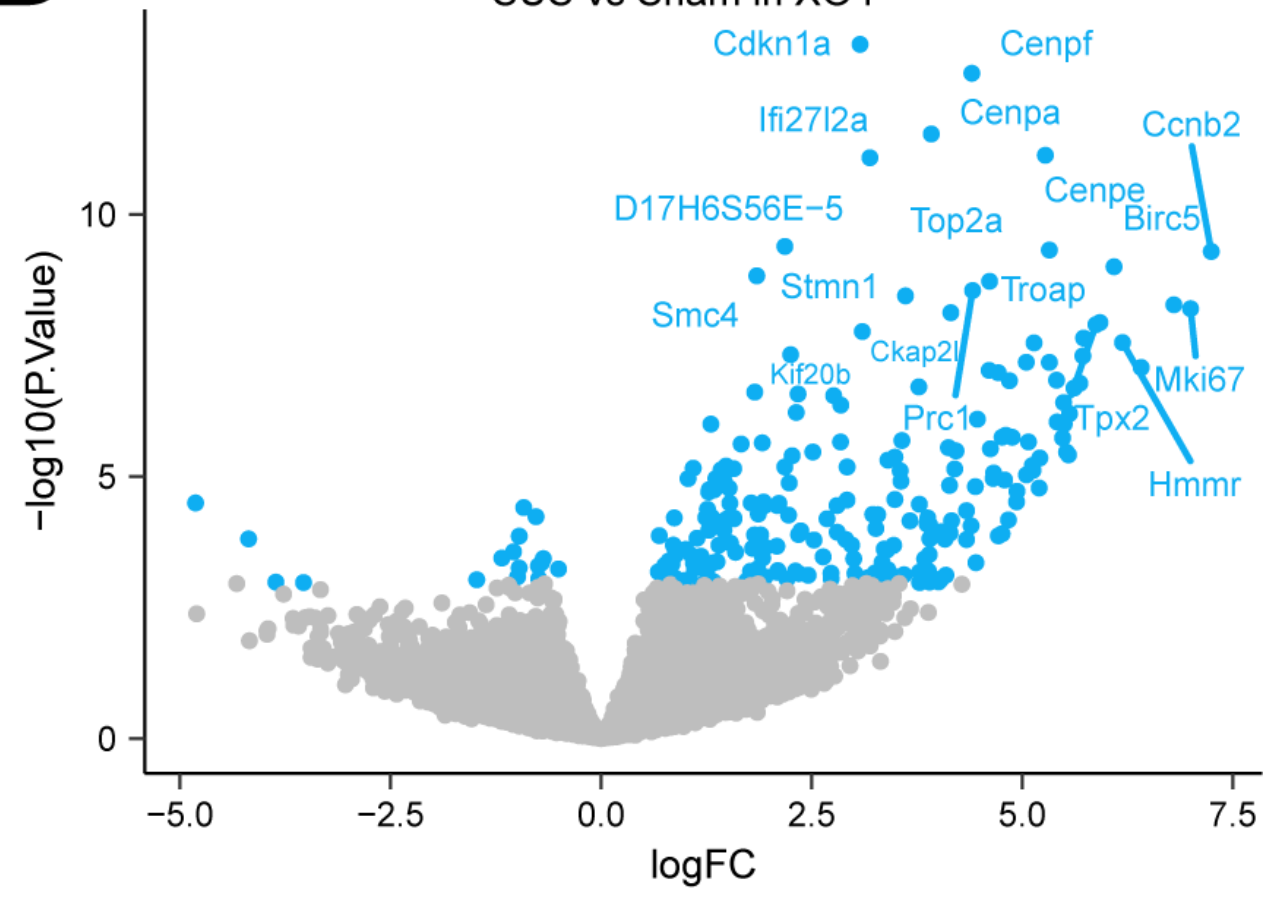


Figure 4. Volcano plots reveal dysregulation of genes in microglia from APP23 mice following SUS ${ }^{+M B}$ or sham treatment. (A) $\mathrm{XO}^{+}$microglia show a large number of genes up-regulated, with the 20 with the largest fold-change (logFC) labeled in magenta. (B) XO4microglia also show a large number of up-regulated genes, with the 20 with the largest foldchange $(\log \mathrm{FC})$ labeled in blue. 


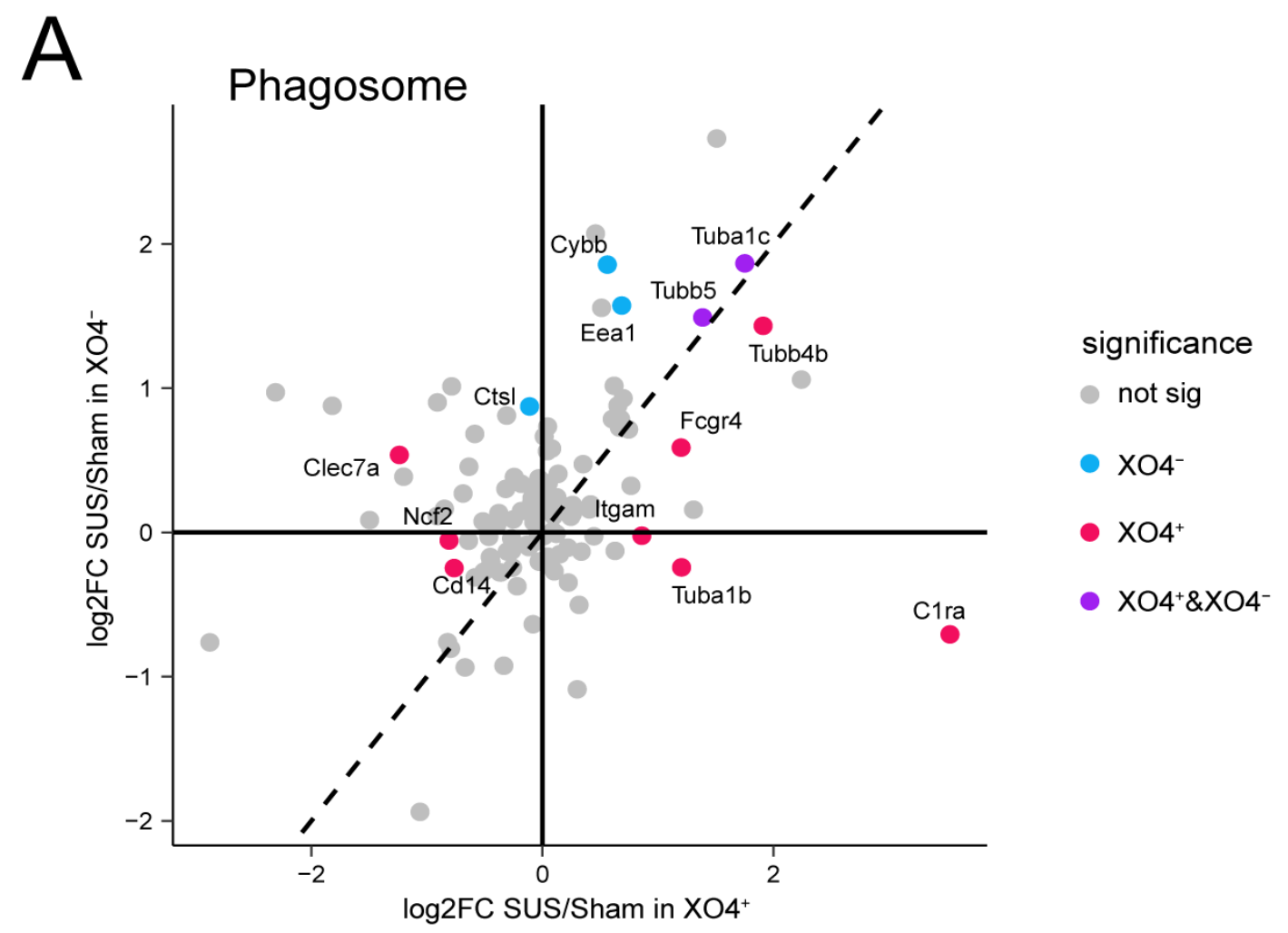

\section{B}

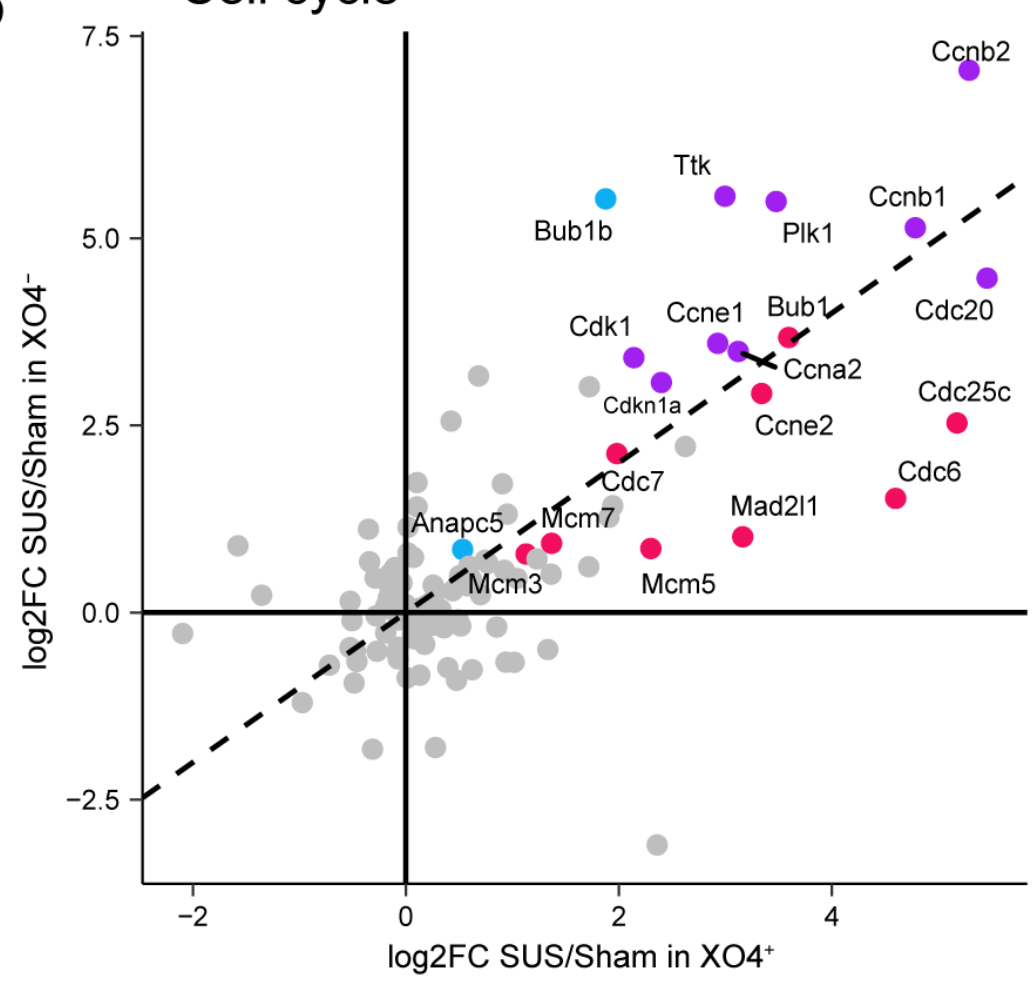

significance

not sig

$\mathrm{XO4}^{-}$

$\mathrm{XO4}^{+}$

$\mathrm{XO4}^{+} \& \mathrm{XO}^{-}$ 
Figure 5. KEGG analysis reveals phagosome and cell cycles as top dysregulated pathways in SUS ${ }^{+M B}$ treated APP23 microglia. (A) Plotting fold-changes in gene expression $(\log 2 \mathrm{FC})$ with $\mathrm{XO}^{+}\left(\mathrm{x}\right.$-axis) and $\mathrm{XO}^{-}$(y-axis) for phagosome genes indicates that the presence of internalized $\mathrm{A} \beta\left(\mathrm{XO}^{+}\right)$in microglia treated with $\mathrm{SUS}^{+\mathrm{MB}}$ leads to an additive effect on this pathway. (B) Plotting fold-changes in gene expression ( $\log 2 \mathrm{FC})$ with $\mathrm{XO}^{+}$(x-axis) and $\mathrm{XO}^{-}$(y-axis) for cell cycle genes reveals that cell cycle genes are upregulated regardless of the presence of internalized $\mathrm{A} \beta\left(\mathrm{XO}^{+}\right)$in microglia cells, with cell cycle genes being enriched in both $\mathrm{XO}^{+}$and $\mathrm{XO}^{-}$cells. Data points are colored according to their statistical significance in the contrasts. 


\section{Tables}

\begin{tabular}{|c|c|c|c|c|c|c|}
\hline Gene symbol & $\log \mathrm{FC}$ & AvgExp & $\mathbf{t}$ & Pval & adj PVal & B \\
\hline Birc5 & 5.76502 & 1.7672889 & 9.02935 & $2.22 \mathrm{E}-10$ & $3.14 \mathrm{E}-07$ & 13.48506 \\
\hline Cdkn3 & 34183 & 5432145 & 6.744088 & $1.18 \mathrm{E}-07$ & 3.49E-05 & 466 \\
\hline Kif11 & 9926 & 0.2461131 & 6.576116 & 1.91E-07 & 5.14E-05 & 6.97426 \\
\hline Ncapg & 5.47342 & -0.1786981 & 5.464827 & $4.88 \mathrm{E}-06$ & 5.93E-04 & 3.988828 \\
\hline Cdc20 & 5.45743 & 1.0739871 & 7.403038 & $1.82 \mathrm{E}-08$ & $8.52 \mathrm{E}-06$ & 9.133173 \\
\hline Nuf2 & 5.32476 & -0.3289444 & 6.736156 & $1.21 \mathrm{E}-07$ & 3.49E-05 & 7.284114 \\
\hline Ccnb2 & 5.2893 & 41487 & 7.553196 & 1.19E-08 & $6.74 \mathrm{E}-06$ & 9.804982 \\
\hline Aurkb & 5.28106 & 98159 & 7.026936 & $5.26 \mathrm{E}-08$ & 2.05E-05 & 8.075848 \\
\hline Cit & 5.24623 & 0.3082589 & 6.415315 & 3.04E-07 & 7.16E-05 & 6.501784 \\
\hline $\mathrm{Hmmr}$ & 5.22306 & 1.186993 & 7.569951 & 1.14E-08 & 6.74 & 9.797002 \\
\hline Esco2 & 5.20983 & 1.0709507 & 4.81764 & $3.25 \mathrm{E}-05$ & 2.80 & 2.353105 \\
\hline Melk & 5.17911 & -0.554891 & 6.172445 & 6.16E-07 & 1.18E-04 & 5.824797 \\
\hline Cdc25c & 482 & 4202 & 5.556821 & 3.73E-06 & 04 & 38965 \\
\hline Kif23 & 702 & 897 & 6.945323 & $6.63 \mathrm{E}-08$ & 2.30 & 7.956364 \\
\hline Nek2 & 204 & 415 & 5.851377 & 1.57E-06 & $2.54 \mathrm{E}-04$ & 4.972077 \\
\hline & 497 & -1.0 & 7.38968 & 1.89E-08 & -06 & 8.82398 \\
\hline Dlg & 637 & 831 & 6.798489 & $1.01 \mathrm{E}-07$ & 3.16 & 7.445236 \\
\hline Tk1 & 171 & 731 & 7.504487 & $1.37 \mathrm{E}-08$ & 7.36 & 9.280781 \\
\hline Mc & 637 & -1.0 & 7.260236 & $2.71 \mathrm{E}-08$ & 05 & 5957 \\
\hline Saa3 & 308 & 763 & 5.045849 & 1.67E-05 & 1.68 & 2.844773 \\
\hline Plac8 & 4.9074 & 802 & 5.889764 & $1.40 \mathrm{E}-06$ & 2.33 & 5.218269 \\
\hline Clspn & 938 & 05 & 6.258953 & 4.79E-07 & 05 & 6.258822 \\
\hline Mk & 598 & 306 & 7.401992 & 1.82E-08 & 8.52 & 9.451222 \\
\hline Cenpk & 418 & 275 & 6.273493 & 4.59E-07 & 9.60 & 6.240974 \\
\hline & 524 & 16 & 6.021465 & E-07 & -04 & 5.65795 \\
\hline & 376 & 72 & 8.35344 & 1.33E-09 & 1.33 & 11.79537 \\
\hline Ndc80 & 4.77516 & 373 & 6.74738 & 1.17E-07 & -05 & 7.549301 \\
\hline & 4.77431 & 171 & 6.30262 & $4.22 \mathrm{E}-07$ & -05 & 6.4019 \\
\hline Mns1 & 059 & 452 & 5.116901 & 5E-05 & 1.40 & 2.98948 \\
\hline Stil & 375 & 108 & 6.896241 & 7.63E-08 & -05 & 7.747276 \\
\hline & 324 & $-0 . \varepsilon$ & 5.791278 & 1.87E-06 & -04 & 4.711205 \\
\hline & 279 & 116 & 8.911432 & 3.03E-10 & -07 & 12.94538 \\
\hline Gpsm2 & 82 & 63 & 5.503262 & E-06 & -04 & 8151 \\
\hline Prc1 & 556 & 75 & 9.092631 & E-10 & -07 & 13.79044 \\
\hline & 4.63601 & 963 & 5.284361 & 8.29E-06 & $9.00 \mathrm{E}-04$ & 3.53967 \\
\hline & & & 5.77 & E-06 & 04 & 482 \\
\hline & 759 & 057 & 6.537217 & 2.14E-07 & 5.62 & 6.96793 \\
\hline Hist1h2 & 674 & 809 & 5.236377 & $9.54 \mathrm{E}-06$ & 1.03E-03 & 3.448414 \\
\hline Cdc6 & 923 & 785 & 5.380778 & $6.25 E-06$ & -04 & 3.650384 \\
\hline & 058 & 768 & 4.66003 & 5.15E-05 & 4.18E-03 & 1.887387 \\
\hline & 722 & 839 & 5.301333 & $7.89 E-06$ & 8.65E-04 & 3.661214 \\
\hline Tpx2 & 441 & 306 & 6.899334 & 7.56E-08 & -05 & 8.057218 \\
\hline Shcbp1 & 333 & 3641 & 6.219989 & 5.36E-07 & 1.06E-04 & 6.048152 \\
\hline & 5075 & 36608 & 4.197819 & $1.95 \mathrm{E}-04$ & $1.29 \mathrm{E}-02$ & 0.699981 \\
\hline Sgol1 & 4.50239 & 653 & 6.068962 & 8.32E-07 & $1.54 \mathrm{E}-04$ & 5.751895 \\
\hline Ckap2l & 4.49338 & 2.7278769 & 7.949218 & 3.99E-09 & $3.22 \mathrm{E}-06$ & 10.8567 \\
\hline Rad51a & 4.43737 & 3958 & 5.761704 & 2.04E-06 & 3.00E-04 & 4.897387 \\
\hline C330027C09Rik & 4.41274 & 3056 & 4.872646 & 2.77E-05 & $2.50 \mathrm{E}-03$ & 2.500517 \\
\hline Ccnf & 4.38312 & 0.9642677 & 5.68638 & $2.55 \mathrm{E}-06$ & 3.43E-04 & 4.605822 \\
\hline Ckap2 & 4.37671 & 0.4264924 & 5.925534 & 1.26E-06 & 2.20E-04 & 5.33635 \\
\hline
\end{tabular}

Table 1. Top 50 dysregulated genes in $\mathrm{XO4}^{+}$microglia from $\mathrm{SUS}^{+\mathrm{MB}}$ vs sham-treated APP23 mice. 


\begin{tabular}{|c|c|c|c|c|c|c|}
\hline Gene symbol & logFC & AvgExp & $\mathbf{t}$ & Pval & adj PVal & B \\
\hline Ccnb2 & 7.2434 & 1.914149 & 8.71212 & $5.11 \mathrm{E}-10$ & $7.22 \mathrm{E}-07$ & 12.5665 \\
\hline Mki67 & 6.99802 & 2.657531 & 7.78265 & $6.32 \mathrm{E}-09$ & 4.76E-06 & 10.315 \\
\hline Cep55 & 6.79948 & 0.164806 & 7.8447 & 5.32E-09 & 4.30E-06 & 9.96164 \\
\hline Nek2 & 6.41184 & -0.839141 & 6.86382 & 8.37E-08 & $3.50 \mathrm{E}-05$ & 7.42704 \\
\hline $\mathrm{Hmmr}$ & 6.18986 & 1.186993 & 7.24982 & $2.80 \mathrm{E}-08$ & 1.46E-05 & 8.78338 \\
\hline Birc5 & 6.08931 & 1.767289 & 8.46022 & 1.00E-09 & 1.26E-06 & 11.9784 \\
\hline Troap & 5.92187 & -1.047597 & 7.56325 & 1.16E-08 & 7.71E-06 & 8.95771 \\
\hline Tpx2 & 5.87434 & 1.396831 & 7.53024 & 1.27E-08 & 7.99E-06 & 9.61853 \\
\hline Digap5 & 5.72789 & -0.379483 & 7.32031 & $2.29 \mathrm{E}-08$ & 1.29E-05 & 8.68108 \\
\hline Stil & 5.71934 & -0.428611 & 7.04233 & 5.03E-08 & 2.37E-05 & 7.82959 \\
\hline Aurkb & 5.68337 & 0.169816 & 6.6225 & 1.67E-07 & 5.90E-05 & 6.88724 \\
\hline Pbk & 5.614 & 0.578285 & 6.5491 & 2.07E-07 & 6.86E-05 & 6.79667 \\
\hline Ttk & 5.56047 & -0.003396 & 6.1612 & 6.36E-07 & $1.75 \mathrm{E}-04$ & 5.66954 \\
\hline Fam64a & 5.54815 & 0.172748 & 5.54325 & $3.88 \mathrm{E}-06$ & 7.30E-04 & 4.21982 \\
\hline Bub1b & 5.52541 & 0.852802 & 5.58235 & $3.46 \mathrm{E}-06$ & $6.62 \mathrm{E}-04$ & 4.21705 \\
\hline Aspm & 5.49894 & 0.778447 & 6.00626 & 9.99E-07 & $2.52 \mathrm{E}-04$ & 5.51711 \\
\hline Plk1 & 5.4907 & 0.714941 & 6.32957 & E-07 & 1.16E-04 & 6.2301 \\
\hline Plac8 & 5.4786 & 1.316802 & 5.79718 & $1.84 \mathrm{E}-06$ & 4.24E-04 & 4.89829 \\
\hline Kif18b & 5.41274 & -0.920601 & 6.03763 & $9.12 \mathrm{E}-07$ & $2.39 \mathrm{E}-04$ & 5.27128 \\
\hline Kif23 & 5.40663 & 0.66509 & 6.66974 & E-07 & $5.45 \mathrm{E}-05$ & 7.16429 \\
\hline Top2a & 5.32157 & 3108 & 8.73594 & $4.80 \mathrm{E}-10$ & $7.22 \mathrm{E}-07$ & 12.923 \\
\hline Psrc1 & 5.32146 & 3526 & 6.94318 & 7E-08 & $2.90 \mathrm{E}-05$ & 7.27514 \\
\hline Cenpe & 5.27386 & 189 & 10.3774 & $\mathrm{E}-12$ & $1.88 \mathrm{E}-08$ & 16.8919 \\
\hline Melk & 5.20793 & -0.554891 & 5.49586 & $4.46 \mathrm{E}-06$ & 7.99E-04 & 3.98286 \\
\hline Brca1 & 5.19986 & 1344 & 5.04746 & E-05 & $2.15 \mathrm{E}-03$ & 2.80218 \\
\hline Ccnb1 & 5.13942 & 4297 & 7.24474 & $4 \mathrm{E}-08$ & $1.46 \mathrm{E}-05$ & 8.78185 \\
\hline Cit & 5.12791 & 8259 & 5.3118 & 5E-06 & 1.17E-03 & 3.51658 \\
\hline $\mathrm{Ccc}$ & 77 & -1. & 5.3 & $E-06$ & $1.08 \mathrm{E}-03$ & 3.52871 \\
\hline $\mathrm{Ndc}$ & 5.07311 & 937 & 5.73685 & E-06 & $4.78 \mathrm{E}-04$ & 4.73085 \\
\hline Kif4 & 5.04925 & -0.560068 & 5.2436 & $9.34 \mathrm{E}-06$ & 1.37E-03 & 3.39874 \\
\hline & 5.04778 & 0.457076 & 6.94527 & E-08 & $2.90 \mathrm{E}-05$ & 7.85063 \\
\hline Efcab11 & 4.93682 & -1.413903 & 4.9978 & 1.92E-05 & $2.38 \mathrm{E}-03$ & 2.61281 \\
\hline Sgol2a & 4.93232 & 0.825684 & 4.83884 & $3.06 \mathrm{E}-05$ & 3.63E-03 & 2.39082 \\
\hline Casc5 & 4.8797 & 1.904732 & 5.80704 & $1.79 \mathrm{E}-06$ & $4.21 \mathrm{E}-04$ & 5.06427 \\
\hline & 4.84763 & 1.543214 & 6.66124 & $1.50 \mathrm{E}-07$ & 5.45E-05 & 7.39483 \\
\hline Ncapg & 4.83529 & -0.178698 & 4.56748 & 6.73E-05 & $6.29 \mathrm{E}-03$ & 1.65013 \\
\hline Arfgap3 & -4.8143 & 3.227787 & -4.82253 & $3.21 \mathrm{E}-05$ & 3.68E-03 & 1.97355 \\
\hline Cdca3 & 4.8047 & 1.033934 & 5.83682 & $1.64 \mathrm{E}-06$ & 4.03E-04 & 5.09039 \\
\hline Polr3g & -4.8016 & 2.483651 & -3.08136 & 4.17E-03 & $1.20 \mathrm{E}-01$ & -1.94254 \\
\hline Nuf2 & 4.79014 & -0.328944 & 5.16747 & 1.17E-05 & 1.63E-03 & 3.13439 \\
\hline Kif11 & 4.76106 & 0.246113 & 5.80768 & $1.79 \mathrm{E}-06$ & $4.21 \mathrm{E}-04$ & 4.99501 \\
\hline Pilrb1 & 4.75962 & -0.129751 & 4.35596 & $1.24 \mathrm{E}-04$ & 1.03E-02 & 1.05207 \\
\hline Fxyd6 & 4.71611 & -1.097719 & 4.32485 & 1.36E-04 & $1.09 \mathrm{E}-02$ & 0.93726 \\
\hline Rrm2 & 4.71417 & 1.554915 & 6.78453 & $1.05 \mathrm{E}-07$ & 4.09E-05 & 7.67497 \\
\hline Kif14 & 4.65924 & -1.058188 & 5.27195 & 8.60E-06 & $1.28 \mathrm{E}-03$ & 3.28961 \\
\hline Spc25 & 4.65365 & 1.777619 & 5.18905 & $1.10 \mathrm{E}-05$ & $1.56 \mathrm{E}-03$ & 3.34028 \\
\hline Omd & 4.62121 & 1.038544 & 5.63473 & $2.96 \mathrm{E}-06$ & 5.98E-04 & 4.39438 \\
\hline Cdca2 & 4.61168 & 1.731777 & 8.22232 & 1.90E-09 & 1.95E-06 & 11.4262 \\
\hline Knstrn & 4.60604 & 1.515975 & 6.81994 & $9.48 \mathrm{E}-08$ & 3.83E-05 & 7.75424 \\
\hline Cdc20 & 4.46665 & 1.073987 & 6.07832 & $8.10 E-07$ & 2.18E-04 & 5.73238 \\
\hline
\end{tabular}

Table 2. Top 50 dysregulated genes in $\mathrm{XO}^{-}$microglia from $\mathrm{SUS}^{+\mathrm{MB}} \mathrm{vs}$ sham-treated APP23 mice. 


\begin{tabular}{lllrrr}
\hline & Term & Ont & N & DE & P.DE \\
\hline GO:0007049 & cell cycle & BP & 1204 & 47 & $4.25 E-15$ \\
GO:0000278 & mitotic cell cycle & BP & 657 & 32 & $1.12 E-12$ \\
GO:0006260 & DNA replication & BP & 203 & 19 & $1.27 E-12$ \\
GO:0022402 & cell cycle process & BP & 838 & 36 & $1.27 E-12$ \\
GO:0006259 & DNA metabolic process & BP & 633 & 31 & $2.39 E-12$ \\
GO:1903047 & mitotic cell cycle process & BP & 544 & 26 & $3.37 E-10$ \\
GO:0006261 & DNA-dependent DNA replication & BP & 113 & 13 & $4.33 E-10$ \\
GO:0007059 & chromosome segregation & BP & 251 & 18 & $4.42 E-10$ \\
GO:0006974 & cellular response to DNA damage stimulus & BP & 618 & 27 & $1.07 E-09$ \\
GO:0044786 & cell cycle DNA replication & BP & 32 & 8 & $1.92 E-09$ \\
GO:0006302 & double-strand break repair & BP & 187 & 15 & $3.05 E-09$ \\
GO:0006281 & DNA repair & BP & 401 & 21 & $4.34 E-09$ \\
GO:0098813 & nuclear chromosome segregation & BP & 196 & 15 & $5.82 E-09$ \\
GO:0006310 & DNA recombination & BP & 203 & 15 & $9.39 E-09$ \\
GO:0000819 & sister chromatid segregation & BP & 153 & 13 & $1.84 E-08$ \\
GO:0033260 & nuclear DNA replication & BP & 28 & 7 & $2.07 E-08$ \\
GO:0000280 & nuclear division & BP & 288 & 17 & $2.65 E-08$ \\
GO:0098687 chromosomal region & CC & 255 & 16 & $3.00 E-08$ \\
GO:0005694 & chromosome & CC & 983 & 32 & $3.27 E-08$ \\
GO:0048285 & organelle fission & BP & 330 & 18 & $3.36 E-08$
\end{tabular}

Table 3. GO pathway enrichment in microglia from $\mathrm{SUS}^{+\mathrm{MB}}$ - versus sham-treated APP23 mice 


\begin{tabular}{llrrl}
\hline & Pathway & $\mathrm{N}$ & DE & P.DE \\
\hline path:mmu03030 & DNA replication & 34 & 6 & $2.13 \mathrm{E}-06$ \\
path:mmu04110 & Cell cycle & 115 & 9 & $6.69 \mathrm{E}-06$ \\
path:mmu00670 & One carbon pool by folate & 17 & 4 & $3.55 \mathrm{E}-05$ \\
path:mmu04114 & Oocyte meiosis & 90 & 5 & $3.76 \mathrm{E}-03$ \\
path:mmu05150 & Staphylococcus aureus infection & 28 & 3 & $3.95 \mathrm{E}-03$ \\
path:mmu04145 & Phagosome & 110 & 5 & $8.73 \mathrm{E}-03$ \\
path:mmu04914 & Progesterone-mediated oocyte maturation & 72 & 4 & $9.42 \mathrm{E}-03$ \\
path:mmu00240 & Pyrimidine metabolism & 39 & 3 & $1.01 \mathrm{E}-02$ \\
path:mmu03013 & Nucleocytoplasmic transport & 96 & 4 & $2.47 \mathrm{E}-02$ \\
path:mmu01523 & Antifolate resistance & 25 & 2 & $3.32 \mathrm{E}-02$ \\
path:mmu03008 & Ribosome biogenesis in eukaryotes & 68 & 3 & $4.34 \mathrm{E}-02$ \\
path:mmu05322 & Systemic lupus erythematosus & 29 & 2 & $4.36 \mathrm{E}-02$ \\
path:mmu04610 & Complement and coagulation cascades & 30 & 2 & $4.64 \mathrm{E}-02$ \\
path:mmu05164 & Influenza A & 119 & 4 & $4.84 \mathrm{E}-02$ \\
path:mmu03440 & Homologous recombination & 34 & 2 & $5.81 \mathrm{E}-02$ \\
path:mmu03460 & Fanconi anemia pathway & 44 & 2 & $9.10 \mathrm{E}-02$ \\
path:mmu05171 & Coronavirus disease - COVID-19 & 163 & 4 & $1.19 \mathrm{E}-01$ \\
path:mmu01240 & Biosynthesis of cofactors & 106 & 3 & $1.23 \mathrm{E}-01$ \\
path:mmu05133 & Pertussis & 53 & 2 & $1.24 \mathrm{E}-01$ \\
path:mmu05140 & Leishmaniasis & 54 & 2 & $1.28 \mathrm{E}-01$
\end{tabular}

Table 4. KEGG pathway enrichment in microglia from SUS $^{+M B}$ - versus sham-treated APP23 mice 